\title{
Cancer Pharmacoethnicity: Ascertaining Chronic Health Outcomes in Survivors of Childhood Cancer in Asia
}

\author{
Yin Ting Cheung* \\ School of Pharmacy, the Chinese University of Hong Kong, Hong Kong
}

Submission: December 11, 2017; Published: December 20, 2017

*Corresponding author: Yin Ting Cheung, School of Pharmacy, Faculty of Medicine, The Chinese University of Hong Kong, Hong Kong, Tel: -852-3943 6833; Email: yinting.cheung@cuhk.edu.hk

\begin{abstract}
The global population of long-term survivors of childhood cancer has grown steadily over the past decades due to advances in modern treatment strategies. Unfortunately, existing evidence demonstrates that survivorship comes at a cost of developing a myriad of treatmentrelated complications that can persist till years after diagnosis. Currently, countries within Asia dominate the largest share of the global cancer burden. While additional progress in treating childhood cancer in Asia is unquestionably necessary, it is anticipated that there will be an emerging population of survivors of childhood cancer over the next decade. However, there is a paucity of studies that evaluates long-term health outcomes in Asian survivors of childhood cancer. Pharmacoethnicity, which refers to ethnic variance in drug response or toxicity, may render divergent health outcomes between Western and Asian cancer survivors. The interaction between genetic and environmental factors may contribute to differences in the development and presentation of chronic toxicities. This opinion piece discusses the urging need for survivorship research that is unique to Asian population. Such knowledge is critical in guiding preventive and rehabilitative interventions that improve health outcomes in survivors of childhood cancer in Asia.
\end{abstract}

Keywords: Childhood cancer; Ethnicity; Genetic; Survivorship; Pharmacogenetics; Pharmacoethnicity

\section{Introduction}

Over the past 40 years, modern treatment strategies have led to tremendous improvements in the five-year survival and cure rates of childhood cancer, particularly in high-income countries within Asia such as Japan, Singapore, South Korea and Hong Kong [1,2]. However, these improvements have not substantially impacted those with limited resources; many countries in the South-Eastern and South-Central Asia still struggle with problems of poor access to timely and affordable treatment and the lack of a locally sustainable pediatric oncology program [2]. While additional progress in treating childhood cancer is unquestionably necessary, the global population of long-term survivors of childhood cancer has grown steadily over the past decades.

Unfortunately, survivorship always comes at a cost of developing a myriad of treatment-related complications that can persist till years after diagnosis [3,4]. These complications include cardiovascular, pulmonary, and metabolic disorders, following predisposing treatment exposures. Therefore, early detection and timely interventions for these late effects are key strategies to improve survivors' functional status and quality of life at the post-treatment phase. However, even though childhood cancer survivorship has gained recognition as an integral component of cancer control continuum in North America, Europe and Oceania, it is still an under-researched and under-addressed area in most regions of Asia. This opinion piece discusses rationales behind the urging need for cancer survivorship research within the Asian region and to provide directions for future research.

\section{Genetic differences in developing late toxicities from anti-cancer treatment}

Currently, there is a paucity of studies that evaluate health outcomes in Asian survivors of childhood cancer and even fewer that focus on identifying the causes and functional impact of these outcomes in Asian survivors. Evidence from the Western population cannot be extrapolated to Asian survivors, as ethnic differences in pharmacogenetics are known to be associated with variation in drug responses and susceptibility to developing adverse outcomes [5]. For example, the NUDT15 
gene is strongly associated with intolerance and elevated acute toxicities of mercaptopurine, which is a common drug used to treat survivors of childhood acute lymphoblastic leukemia $[6,7]$. This genetic variation is commonly observed in patients of East-Asian ancestry, including Japanese, Korean and Chinese populations [8-10]. To highlight, the majority of existing genetic studies are centered around acute toxicities, with less focus on late effects that develop overtime as survivor's age. Determining genetic markers of chronic toxicities in survivors of childhood cancer necessitates systematic assessment of long-term health outcomes in survivors of childhood cancer in Asia.

\section{Cultural differences in environmental factors that influence drug toxicities}

Differences in health behavior and lifestyle may render divergent outcomes between Asian and Western survivors. There exist strong environmental influences that may impact the development of chronic conditions in survivors of childhood cancer. For example, metabolic disorders are associated with previous use of cranial radiation and alkylating agents $[3,11]$. Studies on the Western population have shown that anticancer treatment exacerbates long-term metabolic syndrome in survivors of childhood cancer, through the mediating effect of poor health behaviors such as reduced physical activity and a high-fat diet in the family $[12,13]$. One study in Hong Kong revealed that survivors of childhood cancer displayed significant decline in physical activity levels and the majority of them reported inadequate physical activity [14]. Other culturally relevant extrinsic factors that may influence health include rates of smoking, alcohol use and herbal medicine use. Future studies on late effects should consider the survivor's genetic makeup in the context of environmental and cultural differences in predisposing factors that are important within ethnic groups.

\section{Differences in health literacy level and health delivery systems}

Education and empowerment for this population are crucial as they take up age-appropriate ownership of their health and engage as active partners during the survivorship phase. Sociodemographic determinants and perception of health can strongly influence health literacy levels in survivors and consequently, their independency and initiative in identifying, preventing, and receiving timely interventions for the chronic effects of cancer treatment $[15,16]$. The transition from treatment to survivorship of a child with cancer is often hampered by the absence of an active survivorship program, as well as the lack of practitioners with specialist knowledge of the late complications of childhood cancer [17]. From a macroscopic perspective, countries within Asia adopt varying models of healthcare delivery systems. Even though the overall cancer treatment modalities may be similar across countries, access to quality survivorship care and local practice preferences of health care providers can potentially determine differences in health outcomes and quality of life during the phase of extended survival once cancer treatment is completed. As the majority of survivors are still adolescent and young adults in their early years of survivorship, successful interventions to improve their health and psychosocial outcomes will translate to substantial positive impact on society.

\section{Conclusion}

As survivors of childhood cancer are often lost to follow-up by their primary pediatric clinics due to growing independence and mobility as they advance into adulthood, their needs are often understudied and under-addressed, especially in the context of Asia. There is an urging need for studies that prospectively evaluate health and functional outcomes in Asian survivors of childhood cancer. The eventual goal is to create a repository of outcomes data and biospecimens that can be used to more accurately characterize, and identify treatment, biomedical, social-environmental and genetic predictors of adverse health outcomes in Asian survivors. As long-term follow-up services that provide medical and rehabilitation care for survivors of childhood cancer are now recognized internationally as an essential component of quality cancer care, studies on late effects of cancer can also inform ongoing health surveillance recommendations, and guide the implementation of preventive and rehabilitative interventions that may improve health outcomes in Asian survivors.

\section{References}

1. Allemani C, Weir HK, Carreira H, Harewood R, Spika D, et al. (2015) Global surveillance of cancer survival 1995-2009: analysis of individual data for $25,676,887$ patients from 279 population-based registries in 67 countries (CONCORD-2). Lancet 385(9972): 977-1010.

2. Rodriguez-Galindo C, Friedrich P, Alcasabas P, Antillon F, Banavali S, et al. (2015) Toward the Cure of All Children With Cancer Through Collaborative Efforts: Pediatric Oncology As a Global Challenge J Clin Oncol 33(27): 3065-3073.

3. Bhakta N, Liu Q Ness KK, Baassiri M, Eissa H, et al. (2017) The cumulative burden of surviving childhood cancer: an initial report from the St Jude Lifetime Cohort Study (SJLIFE). Lancet S0140-6736(17): 3161031610.

4. Hudson MM, Ness KK, Gurney JG, Mulrooney DA, Chemaitilly W, et al. (2013) Clinical ascertainment of health outcomes among adults treated for childhood cancer. JAMA 309(22): 2371-2381.

5. Syn NL, Yong WP, Lee SC, Goh BC (2015) Genetic factors affecting drug disposition in Asian cancer patients. Expert Opin Drug Metab Toxicol 11(12): 1879-1892.

6. Yang JJ, Landier W, Yang W, Liu C, Hageman L, et al. (2015) Inherited NUDT15 variant is a genetic determinant of mercaptopurine intolerance in children with acute lymphoblastic leukemia. J Clin Oncol 33(11): 1235-1242.

7. Singh M, Bhatia P, Khera S, Trehan A (2017) Emerging role of NUDT15 polymorphisms in 6-mercaptopurine metabolism and dose related toxicity in acute lymphoblastic leukaemia. LeukRes 62: 17-22.

8. Wong FC, Leung AW, Kwok JS, Chan MH, Li CK, et al. (2016) NUDT15 variant and thiopurine-induced leukopenia in Hong Kong. Hong Kong Med J 22(2): 185-157.

9. Moriyama T, Nishii R, Lin TN, Kihira K, Toyoda H, et al. (2017) The effects of inherited NUDT15 polymorphisms on thiopurine active metabolites in Japanese children with acute lymphoblastic leukemia. Pharmacogenet Genomics 27(6): 236-239. 
10. Kim HT, Choi R, Won HH, Choe YH, Kang B, et al. (2017) NUDT15 genotype distributions in the Korean population. Pharmacogenet Genomics 27(5): 197-200

11. Mostoufi-Moab S, Seidel K, Leisenring WM, Armstrong GT, Oeffinger $\mathrm{KC}$, et al. (2016) Endocrine Abnormalities in Aging Survivors of Childhood Cancer: A Report From the Childhood Cancer Survivor Study. J Clin Oncol 34(27): 3240-3247.

12. Gibson TM, Ehrhardt MJ, Ness KK (2016) Obesity and Metabolic Syndrome Among Adult Survivors of Childhood Leukemia. Curr Treat Options Oncol 17(4): 17.

13. Smith WA, Li C, Nottage KA, Mulrooney DA, Armstrong GT, et al. (2014) Lifestyle and metabolic syndrome in adult survivors of childhood cancer: a report from the St. Jude Lifetime Cohort Study. Cancer 120(17): $2742-2750$
14. Chung OK, Li HC, Chiu SY, Ho KY, Lopez V (2014) The impact of cancer and its treatment on physical activity levels and behavior in Hong Kong Chinese childhood cancer survivors. Cancer Nurs 37(3): 43.

15. Lin M, Sansom-Daly UM, Wakefield CE, McGill BC, Cohn RJ (2017) Health Literacy in Adolescents and Young Adults: Perspectives from Australian Cancer Survivors. J Adolesc Young Adult Oncol 6(1): 150158.

16. Poplack DG, Fordis M, Landier W, Bhatia S, Hudson MM, et al. (2014) Childhood cancer survivor care: development of the Passport for Care. Nat Rev Clin Oncol 11(12): 740-750.

17. McCabe MS, Partridge A, Grunfeld E, Hudson MM (2013) Risk-Based Health Care, the Cancer Survivor, the Oncologist and the Primary Care Physician. Semin Oncol 40(6): 804-812.

\section{Your next submission with Juniper Publishers} will reach you the below assets

- Quality Editorial service

- Swift Peer Review

- Reprints availability

- E-prints Service

- Manuscript Podcast for convenient understanding

- Global attainment for your research

- Manuscript accessibility in different formats

( Pdf, E-pub, Full Text, Audio)

- Unceasing customer service

Track the below URL for one-step submission https://juniperpublishers.com/online-submission.php 